\title{
Instabilities in Braided Textile Composites Under Uniaxial Compressive and Biaxial Loadings
}

\author{
Shu Ching Quek* and Anthony M. Waas ${ }^{\dagger}$ \\ Composite Structures Laboratory, \\ Department of Aerospace Engineering \\ University of Michigan, Ann Arbor, MI 48109-2140 \\ Khaled Shahwan and Venkatesh Agaram \\ DaimlerChrysler Corporation \\ 1000 Chrysler Drive \\ Auburn Hills, MI 48326-2766
}

\begin{abstract}
This paper discusses the results of a finite element (FE) based study of the multiaxial compressive instabilities in braided glass fiber composites. The micro mechanics study was carried out on a 2-unitcell size 3-D FE model. Computational tests were carried out to first determine the elastic moduli of the system. Once the computational model was validated with experimental data for the elastic moduli, the uniaxial compressive response of the micromodel was established using the RIKS option available in the ABAQUS commercial FE code. Subsequently, the response of the micromodel to biaxial loading was investigated. The present approach is different from those reported in the literature where classical methods based on the technique of homogenization is used to model the elastic and inelastic response of braided composites. In this work, explicit account of the braid microstructure (geometry and packing) and the inelastic properties of the matrix are accounted for via the use of the FE method. The macromechanical data pertaining to the braided composites were obtained through traditional means. Tensile tests were
\end{abstract}

performed on the composites through the use of ASTM D 3039 standard to obtain the macroscopic orthotropic moduli and macroscopic response. For each test, the average data is reported in this paper. A separate test was conducted to obtain the in-situ matrix properties of the braided glass composites. The computational model provides a means to assess the compressive and biaxial strength of the braided composites and its dependence on various microstructural parameters. It also serves as a tool to assess the most significant parameter that affects compressive strength.

\section{Introduction}

Since the early 80 's, a considerable amount of literature dealing with braided composites has been reported in the open literature. Whitcomb and Noh [1], Naik and Stembekar [2], Huang [3], Naik [4] and Cox and Dadkhah [5] have proposed models to predict the elastic moduli of textile composites in general. Such models were based on the concept of using a smallest representative unit that will describe the architecture of the textile composite and by

\footnotetext{
${ }^{*}$ Graduate Student Research Assistant

${ }^{\dagger}$ Professor of Aerospace Engineering, Associate Fellow AIAA
} 
applying suitable schemes, appropriate to achieving a desired end result. These methods are dependent on the method of unitcell discretization and also on the particular averaging scheme that is used to define the required macroscopic unit cell property.

An alternate procedure that can be used to eliminate some of the dependency (on the particular method used) is to base the definition of macroscopic properties on the measured (actual) geometrical and mechanical properties of the textile composites' constituents. The solution of the boundary value problem/s thus posed is/are obtained by resorting to a numerical technique, such as the finite element method.

In the present paper, the response and failure of glass triaxial braided composites (GTBC) are studied via the finite element method. A micromodel (two unit cell) incorporating measured geometry and nonlinear material properties is meshed using the commercial software SDRC IDEAS Master Series 8. 3 D solid elements are used for the tows and the matrix material. The response of the micromodel under uniaxial and multiaxial loading conditions was established using the RIKS method option available in ABAQUS. A similar approach has been successfully used for the study of compressive failure and compressive strength of continuous fiber laminated composites by Ahn and Waas [6]. The predictions of the computational model for the multiaxial compressive strength of braided composites and the dependence of strength on tow misalignments are presented and discussed. To the best knowledge of the authors, this is the first publication related to the prediction of compressive / biaxial material strength in the manner described.

\section{Properties and Architecture of the Glass Triaxially Braided Composite (GTBC)}

\subsection{Macroscale measurements}

Using the ASTM D 3039 standard, uniaxial tensile tests were performed on the composites, to obtain the macroscopic orthotropic moduli and response. For each test, 3 samples were used to ensure accuracy and the average of the data is reported in this paper. A separate test was conducted to obtain the insitu matrix properties of the braided glass composites. The in-situ matrix properties will be discussed later. Table 1 and Table 2, show the fiber, resin type and the measured elastic moduli of the GTBC.

\subsection{Microscale measurements}

To more easily observe the braided tows of glass fibers, an image of the braided mat (dry preform) without the resin is shown in Figure 1. The outlined area is the smallest representative unit cell (RUC) found within the triaxial braids. Bias tows are weaved at $30^{\circ}$ to the vertical axis. At least 6 measurements were made throughout the mat to obtain average values of each key dimension used to reconstruct the GTBC microstructure for the purpose of finite element (FE) modeling. The key dimensions consist of the wavelength, $2 \lambda$, amplitude, $A$, axial tow cross sectional dimensions, $a \times b$ and bias tow cross sectional dimensions, $a_{b} \times b_{b}$, (Figure 1). The tows are assumed to have an elliptical cross-section and this assumption has been verified via scanning electron microscope images.

\section{Finite Element Modeling of RUC}

Most researchers within the field of composite mechanics use a macromechanical approach to establish composite mechanical properties. Implicit in such an approach, is the assumption that the composite material is homogeneous (at the scale of the RUC) in nature and thus the instantaneous (tangent) moduli obtained are averaged over the volume of the particular representative unit cell (RUC). This implies that no local information will be available inside the RUC of the composite. Such "homogenized" approaches find difficulty in extension to situations that warrant modeling failure mechanisms, such as matrix cracking and fiber/tow debonding. These mechanisms require knowledge of the local stress and strain fields and this information cannot be obtained when the composite is treated as a homogeneous medium.

\subsection{Creation of Micromodel}

The micromodel in the present work was built using the commercial software package SDRC-IDEAS Master Series 8. Due to the complexity of the geometry, a sophisticated CAD tool and a finite element meshing tool is required. The micro architecture of the GTBC is shown in Figure 2.

The effects of mesh density on the obtained results were not investigated due to geometrical constraints within the model. Instead, the adequacy of the mesh was verified via comparison of the micromodel mechanical properties with measured experimental data. The size of elements used for 
meshing (and thus the mesh density) was controlled by the gaps and spaces of the actual braid architecture. Consequently, the smallest element size was set by the minimum spacing between the tows and the matrix at certain locations within the RUC. The spacing between the zero tows and bias (angle) tows were such that element dimensions less than $0.02 \mathrm{~mm}$ could not be used to generate the mesh. In order to have matching boundaries between one segregated volume and another, similar element sizes had to be used. To accommodate this 'element size' issue and given the present computational power available, the results are presented with the optimal mesh density that is sufficiently fine, so as not to create severe element distortion errors and violate small geometrical clearances.

\subsection{Assumptions made during modeling of the microstructure}

Table 4 shows properties of glass fibers and the epoxy matrix. In order to create the micromodel of the $-30^{\circ} / 0^{\circ} /+30^{\circ}$ GTBC, several assumptions had to be made.

The tows were treated as one entity with the assumption of transverse isotropy. That is, the tows are assumed to be a 3-D curved solid. The tow properties were generated using the values found in Table 4. Tow cross sectional area corrections were made when a smaller value was used due to geometrical constraints during FE modeling of the microstructure. This was necessary to provide a bigger spacing between the axial tows and the bias tows. As such, the element size for the matrix need not be so small that the model will end up having too many elements that cannot be handled by the present available computational power. Equation 1 describes the formula for the area corrections.

$E_{1}^{*}=\frac{A_{1}}{A_{1}^{*}} E_{1}$

$E_{1}$ is the original modulus corresponding to $A_{1}$. A superscript '*', corresponds to the corrected modulus corresponding to the new area. Other tow properties are based on a $10 \%$ matrix volume fraction, that is $V_{f}$ $=0.9$. A series of equations below describes all the required properties for the tow. Details can be found in Herakovich[7].

$E_{1}=E_{f} V_{f}+E_{m}\left(1-V_{f}\right)$
$\frac{1}{E_{2}}=\frac{V_{f}}{E_{2}^{f}}+\frac{\left(1-V_{f}\right)}{E_{m}}$

$\frac{E_{2}}{E_{1}}=\frac{v_{21}}{v_{12}}$

$\frac{1}{G_{12}}=\frac{V_{f}}{G_{12}^{f}}+\frac{\left(1-V_{f}\right)}{G_{12}^{m}}$

A superscript or subscript ' $f$ ' signifies fiber properties while ' $m$ ' signifies matrix properties.

In order to obtain the stability of compressive response of the GTBC, nonlinear constituent properties of the matrix are required for finite deformation. For this purpose, the virgin matrix material is modeled as an elastic-plastic solid obeying $\mathrm{J} 2$ incremental theory of plasticity. For this purpose, the nonlinear uniaxial response of the matrix material was measured and used in conjunction with the *PLASTIC option available in ABAQUS.

\subsection{In-situ matrix properties}

It is well established that the in-situ response of the polymer matrix in a braided composite has effective properties that are different than the virgin resin material, due to (unwanted) residual stresses. In order to be as accurate as possible, tests were carried out to determine the in-situ matrix properties. Again, the standard ASTM-D 3039 uniaxial test was conducted on a $\left(-45^{\circ} /+45^{\circ}\right)_{8}$ continuous fiber composite laminate made from the same resin. Strain gages were placed as shown in the schematic diagram (Figure 3).

A shear stress versus shear strain plot is generated from the results obtained from this test. This is in turn used to produce a plot of tangent shear modulus against shear stress. Using the Halphin-Tsai relations [8], and after some manipulation, we obtain the relation between the tangent shear modulus of the in situ matrix and the composite tangent modulus as

$G_{m}=G_{12} \frac{\left(G_{12 f}+G_{m}\right)-v_{f}\left(G_{12 f}-G_{m}\right)}{\left(G_{12 f}+G_{m}\right)+v_{f}\left(G_{12 f}-G_{m}\right)}$

Integrating this data provides the shear response data for the matrix. This data is manipulated in conjunction with the assumptions of $\mathrm{J} 2$ incremental theory of plasticity to obtain the uniaxial stress-strain 
relation for the in-situ matrix. Figure 4 shows the results obtained for the in-situ matrix shear response.

Figure 5 shows the difference in the predicted matrix and the experimentally obtained in-situ matrix response. Both matrix responses were used in the computational model and the effect this has on the response of each micromodel is presented in the "Results and Discussion" section.

\subsection{Boundary conditions of micromodel and imperfections imposed}

The micromodel consists of two unit cells. Planar (2D) views of the micromodel and the loading under displacement control conditions used to obtain the linear elastic response (and the corresponding orthotropic moduli) are as shown in Figure 6. For the response analysis using the RIKS method, results were first obtained for uniaxial compression in the $\mathrm{x}$ direction. Several response analyses were conducted on a series of imperfect micromodels. The imperfections were generated by first deforming the micromodel by a small known amount. This step (Load Step 1), was done by displacing the points $\mathrm{L}$ and $\mathrm{M}$ of the end face EFGH (Figure 7) by an amount $\delta$ in the $y$ and $z$ directions. During this step, the points $\mathrm{J}$ and $\mathrm{K}$ of the face ABCD are held fixed, while all other nodes of the micromodel are left unconstrained. Each value of $\delta$ produces an imperfect micromodel. Since the $0^{\circ}$ tow is lying along the $\mathrm{x}$-direction, this initial load step provides a misalignment of the main $0^{\circ}$ tow. Next, a response analysis for each imperfect micromodel was carried out (Load Step 2). During this step, all nodes of face $\mathrm{ABCD}$ are restrained from motion in the $\mathrm{x}$-direction, while points $\mathrm{J}$ and $\mathrm{K}$ are fixed. Points $\mathrm{M}$ and $\mathrm{L}$ are fixed in the $\mathrm{y}$ and $\mathrm{z}$ directions, while the nodes on the face EFGH are specified to move only in the negative $\mathrm{x}$-direction.

The response of the micromodel to biaxial proportional loading was also investigated. As for the uniaxial compression loading case, initially the micromodel was deformed by a small known amount. This step (load step 1) was done by displacing the points $\mathrm{L}$ and $\mathrm{M}$ of the end face of EFGH (Figure 7) by $0.004 \mathrm{~mm}$ in the $\mathrm{y}$ and $\mathrm{z}$ directions. During this step, the points $\mathrm{J}$ and $\mathrm{K}$ of the face $\mathrm{ABCD}$ are held fixed. Next a response analysis was carried out in a proportional manner. By doing this, the faces EADH, FBGC, EFGH and, $\mathrm{ABCD}$ remain flat in the deformed configuration. Faces EADH and FBGC remain parallel to each other after deformation and the same is true for faces ABCD and EFGH. Several proportional compressive-tensile load paths were studied. Results obtained from these studies are presented in the next section.

\section{Results and Discussion}

\subsection{Elastic moduli verification of micromodel}

Table 5 shows the comparison between experimental and computational results for the orthotropic elastic moduli. The computational results obtained are in close agreement with the measured experimental values. It is to be noted that the experimental uniaxial specimens contain several unit cells in the gage section and the close agreement attests to the homogeneous deformation assumption, implicit in the measurement of properties through a uniaxial ASTM D 3039 standard test. The results for moduli obtained via the computational micromodel also rely on definitions of macroscopic stress and strain that is based on the micromodel. For example, for the determination of $E_{x}$, the macroscopic stress, $\Sigma_{x}$ is defined as the sum of reaction forces on face ABCD divided by the area $A B C D$, and macroscopic strain, $\varepsilon_{\mathrm{x}}$ is defined as total elongation of the unit cell divided by the length in the direction of elongation. The good correlation between computation and measurement points to an increased level of confidence in the meshing and construction of the micromodel as well as to the accuracy of the assumptions made regarding simplifications to the modeling of the tows.

\subsection{Instabilities of micro architecture within the $-30^{\circ} / 0^{\circ} /+30^{\circ} \mathrm{GTBC}$}

Accurate predictions of the elastic moduli provide verification of the computational model. As explained earlier, a two-step approach was used to carry out the compressive response analysis of the micromodel using the RIKS method option in ABAQUS, namely,

- $\quad$ Load step 1

Introduce a misalignment of the $0^{\circ}$ tow (or the axial tow) as explained earlier.

- $\quad$ Load step 2

Analyze the model using nonlinear geometry, nonlinear material properties in conjunction with the RIKS method.

The results obtained from the uniaxial compressive response study for a series of different imperfection magnitudes are plotted in Figure 8. 
The uniaxial compressive response of the micromodel predictions can be understood by examining the $\Sigma_{\mathrm{x}}$ versus $\varepsilon_{\mathrm{x}}$ plot. Initially, all the micromodels display a relatively stiff linear behavior. The magnitude of the slope of this line for all the imperfect micromodels is $27 \mathrm{GPa}$ and agrees with the tensile experimental data.

As seen in Figure 8, with continued loading, the micromodel response becomes progressively nonlinear, and at a strain $\left(\varepsilon_{\mathrm{x}}\right)$ of approximately 0.035 , a maximum stress $\left(\Sigma_{\mathrm{x}}\right)$ of 72,000 psi is reached with an imperfection of $0.01 \mathrm{~mm}$. The value of strain at this maximum or peak and the value of the corresponding stress itself are dependent on the magnitude of $\delta$, which is associated with the degree of misalignment of the zero degree tow. The progressive reduction in the macroscopic stiffness is due to the geometrical nonlinearity associated with the bias tows and the main zero degree tow as well as with the material nonlinearity of the in-situ matrix. Indeed, as loading proceeds, the matrix material that is between the tows is required to support increasing amounts of shear stress. However, the equivalent stress-strain curve of the matrix indicates that the matrix modulus decreases progressively as the stress increases. Thus, because of the interaction of these nonlinearities, the overall stiffness of the micromodel progressively decreases leading to a limit load type instability. In an experimental setting, this limit load can be interpreted as the maximum compressive strength. However, at this load, other events, such as matrix cracking and separation of the tows from the matrix (matrix/tow debonding) occur, which lead to the surface angle tows "popping out", as is characteristically seen in a compression experiment at failure (Figure 9). The modeling of matrix cracking and tow/matrix separation requires knowledge of the matrix cracking toughness and the tow-matrix interface toughness. These mechanisms are currently being modeled through a cohesive zone approach, Shawan and Waas [9].

Subsequent to the limit load, the axial stress is seen to diminish along with increasing amounts of axial strain (actually it is possible for both the stress and the strain to decrease simultaneously, due to the arc length tracing RIKS method that is adopted in ABAQUS). Thus, the micromodel response is stable. Eventually, the rate of decrease of stress levels off to a near constant plateau stress.
Figure 10 shows the change of maximum stress as a function of imperfection magnitude, and Figure 11 shows the same for the plateau stress. While the maximum stress appears to converge, the plateau stress does not. This is because the plateau stress is continually dependent on the extent (volume) of material that undergoes damage and with increasing stress level, larger portions of the matrix material in the micromodel are subjected to plastic straining.

\subsection{Effects of Instabilities with Biaxial Loadings}

Figure 12 shows the responses of a series of numerical tests under different proportional biaxial loads. As the ratio of tension to compression increases, the maximum compressive load decreases and shifts towards the increasing $\sigma_{y}$ direction.

This trend is also seen in the experiments conducted. Since there was a limited supply of glass braided composite material available, only a few tests were conducted for obtaining the corresponding failure envelope. The biaxial tests were carried out in a special loading fixture that is capable of applying proportional compression-tension biaxial loading in the manner that has been studied with the micromodel. It is to be noted that the experiments are conducted on material plaques that contain several unitcells. Figure 13 and Figure 14 show the experimental and computational failure points respectively. Although the curves do not match, the trend is observed to be the same. Some of the reasons for the higher failure loads predicted through the numerical simulations are discussed next.

Recall that the micromodel captures the instability within 2 unitcells, with the loading faces constrained to remain flat during the loading process. This implies that failure is occurring on all cells of the structural specimen in the experiment. As indicated in Figure 9, the maximum compressive load is associated with deformation localization, occurring within a few cells. Thus, it is conceivable that unitcell failure models corresponding to proportional compressiontension (pressure control) would lead to lower numerical prediction. This aspect is currently being studied. The tows within the micromodel were assumed to be transversely isotropic and linear elastic, yet, in reality these tows contain matrix material that is stressed into nonlinear regime. Consequently, the tows should be modeled within the framework of an appropriate transversely isotropic elastic-plastic characterization. A generalization of the Hill orthotropic elastic-plastic model as proposed by Sun 
and Chen [10] is being considered for this purpose. This modeling feature will also result in a lowering of the predicted compressive strength. Finally, matrix cracking occurring prior to tow instability should also be accounted for in the modeling of textile composites. A thermodynamically consistent damage mechanics formulation for this purpose has been proposed by Schapery and Sicking [11]. The implementation of such a formulation requires that the matrix cracking phenomenon be suitably characterized via coupon level tests. This is planned for the future.

\section{Conclusions}

Compressive instabilities of braided glass fiber composites in a multiaxial setting have been studied. A computational model has been described and is found to be capable of predicting compressive strength of the braided composite under various types of loading. Inputs to the model are fiber/tow architecture of the braid, the elastic properties of the fiber, the fiber volume fraction and the complete nonlinear stress-strain response of the matrix. Using only these inputs, the objective of predicting compressive strength of the material, and its dependence on tow misalignment was achieved. Although we have predicted describing the change of strength under different load ratios, only the qualitative aspects of the problem have been captured. The extension of this model to incorporate tow material nonlinearity, matrix cracking and tow/matrix separation is currently being pursued and will impact the predictive capability in a positive way.

\section{Acknowledgements}

We are grateful to the Automotive
Composites Consortium Energy Management
Working Group (ACC-EMWG) for supplying the
material used in the present study. SCQ and AMW
acknowledge the financial support from the ACC-
EMWG and the Aerospace Engineering Department
at the University of Michigan.

\section{References}

1. Whitcomb, J. and Noh, J, (2000). "Concise Derivation of Formulas for 3D Sublaminate Homogenization”. Journal of Composite Materials, 34, pp 522-535.

2. Naik, N.K. and Stembekar, P.S., 1992, "Elastic Behavior of Woven Fabric Composites : I -
Lamina Analysis". Journal of Composite Materials, 26, pp 2196-2225.

3. Huang, Z. M., (2000). "The mechanical properties of composites reinforced with woven and braided fabrics". Composites Science and Technology, 60, pp 479-498.

4. Naik, R., (1996). "Analysis of 2D triaxial and 3D multi-interlock braided textile composites". 37 $7^{\text {th }}$ AIAA/ ASME/ ASCE/ AHS/ASC Structures, Structural Dynamics and Materials Conference.

5. Cox, B.N. and Dadkhah M.S., (1995). The macroscopic elasticity of 3D woven composites. Journal of Composite Materials, 29, pp 785-819.

6. Ahn, J. H. and Waas, A. M., 1999. "A Micromechanical-Based Finite Element Model for Compressive Failure of Notched Uniply Composite Laminates Under Remote Biaxial Loads". Journal of Engineering Materials and Technology, 121, pp 360-366.

7. Herakovich, C.T., (1998). "Mechanics of Fibrous Composites”. McGraw-Hill, New York.

8. Ahn, J. H., (1999). "Failure Mechanisms of Notched Laminated Composites under Compressive Loading at Room and Elevated Temperature". Ph.D Dissertation at the University of Michigan.

9. Shahwan, K. and Waas, A. M., (1997). "Non-selfsimilar decohesion along a finite interface of unilaterally constrained delamination”. Proc. R. Soc. London, 453, pp 515-550.

10. Sun, C.T. and Chen, J.L., (1989). "A Simple Flow Rule for Characterizing Nonlinear Behavior of Fiber Composites". Journal of Composite Materials, vol. 23, pp 1009-1021.

11. Schapery, R.A. and Sicking, D.L., (1995). "On Nonlinear Constitutive Equations for Elastic and Viscoelastic Composites with Growing Damage”. Mechanical Behaviour of Materials, pp 45-76. 


\begin{tabular}{|l|l|c|l|c|}
\hline \multicolumn{5}{|c|}{ Material Name: Braided $\mathbf{- 3 0} \% \mathbf{0}^{\circ} / \mathbf{3 0}^{\circ}$ Glass Fiber Polyvinylester Composite } \\
\hline \multicolumn{1}{|c|}{ Fiber } & \multicolumn{1}{|c|}{ Resin } & $\begin{array}{l}\text { No. of } \\
\text { Plies }\end{array}$ & Thickness & $\begin{array}{c}\text { Volume } \\
\text { Fraction }\end{array}$ \\
\hline \hline $\begin{array}{l}\text { E-Glass (Owens } \\
\text { Corning) }\end{array}$ & $\begin{array}{l}\text { Dow Spectrum MM364 } \\
\text { Isocyanurate }\end{array}$ & 3 & $\begin{array}{l}0.214 \text { in } \\
5.0 \mathrm{~mm}\end{array}$ & $45 \%$ \\
\hline
\end{tabular}

Table 1: Fiber and Resin Type

\begin{tabular}{|l|r|}
\hline \multicolumn{1}{|c|}{ Properties } & Experimental Data \\
\hline $\mathrm{E}_{\mathrm{z}}$ & $12.89 \mathrm{GPa}$ \\
& $1.87 \mathrm{Msi}$ \\
\hline $\mathrm{E}_{\mathrm{x}}$ & $27.18 \mathrm{GPa}$ \\
& $3.94 \mathrm{Msi}$ \\
\hline $\mathrm{G}_{\mathrm{xz}}$ & $4.80 \mathrm{GPa}$ \\
& $0.70 \mathrm{Msi}$ \\
\hline
\end{tabular}

Table 2: Elastic moduli of glass triaxially braided composite

* Note that the value of $\mathrm{G}_{\mathrm{xy}}$ is provided by supplier and not measured by ACL. The measured values for the other moduli were generally higher; approximately $10 \%$ higher.

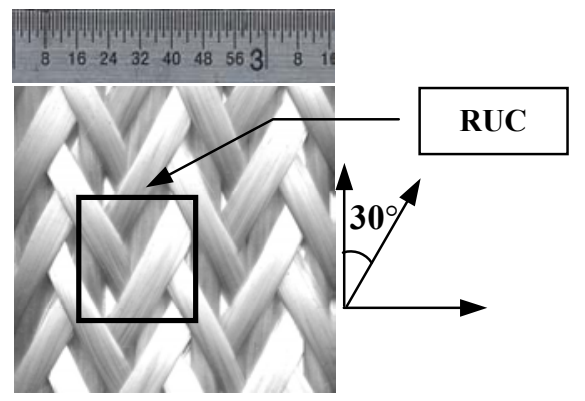

Bias Tow Cross-section Axial Tow Cross-section

Figure 1: Fiber glass braided mat without resin and key dimensions

\begin{tabular}{|c|c|c|c|}
\hline$\lambda$ & $\boldsymbol{A}$ & $\boldsymbol{a} \times \boldsymbol{b}$ & $\boldsymbol{a}_{\boldsymbol{b}} \times \boldsymbol{b}_{\boldsymbol{b}} \cdot$ \\
\hline $14.030 \mathrm{~mm}$ & $0.701 \mathrm{~mm}$ & $3.012 \mathrm{~mm} \times 0.503 \mathrm{~mm}$ & $3.010 \mathrm{~mm} \times 0.498 \mathrm{~mm}$ \\
\hline
\end{tabular}

Table 3: Key dimensions of $-30^{\circ} / 0^{\circ} /+30^{\circ}$ GTBC 

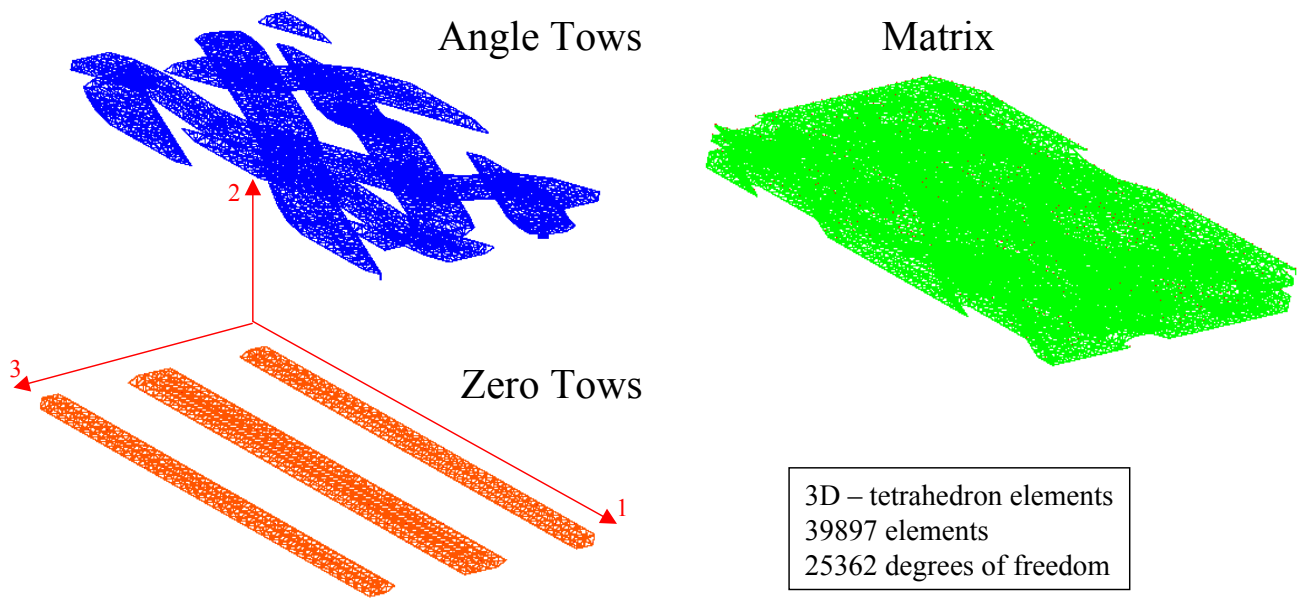

Figure 2: Finite element model of $-30^{\circ} / 0^{\circ} / 30^{\circ}$ GTBC

\begin{tabular}{|l|c|c|c|}
\hline \multicolumn{1}{|c|}{ Material } & E (GPa) & G (GPa) & U \\
\hline $\begin{array}{l}\text { Matrix : Epoxy (Dow } \\
\text { Spectrum MM364) }\end{array}$ & 5.0 & 1.83 & 0.36 \\
\hline $\begin{array}{l}\text { Fibers : E-Glass (Owens } \\
\text { Corning) }\end{array}$ & 72.4 & 29.67 & 0.22 \\
\hline
\end{tabular}

Table 4: Properties of constituents.

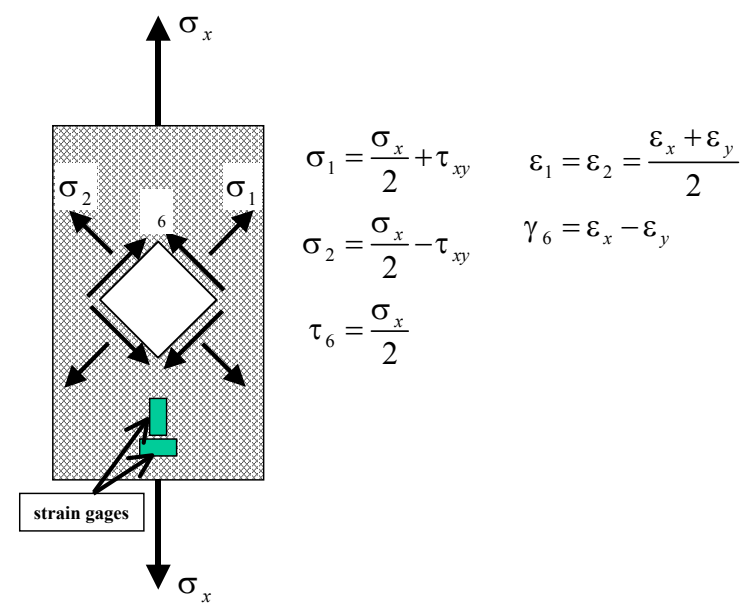

Figure 3: Schematic diagram of the test section and it's corresponding stress state equations 


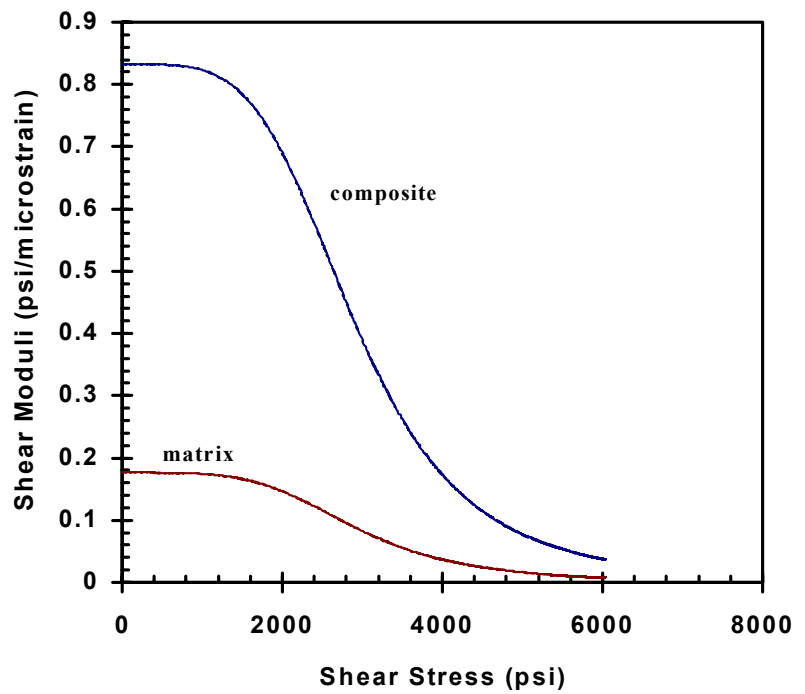

Figure 4: Shear Modulus versus shear stress for the in-situ matrix and the composite

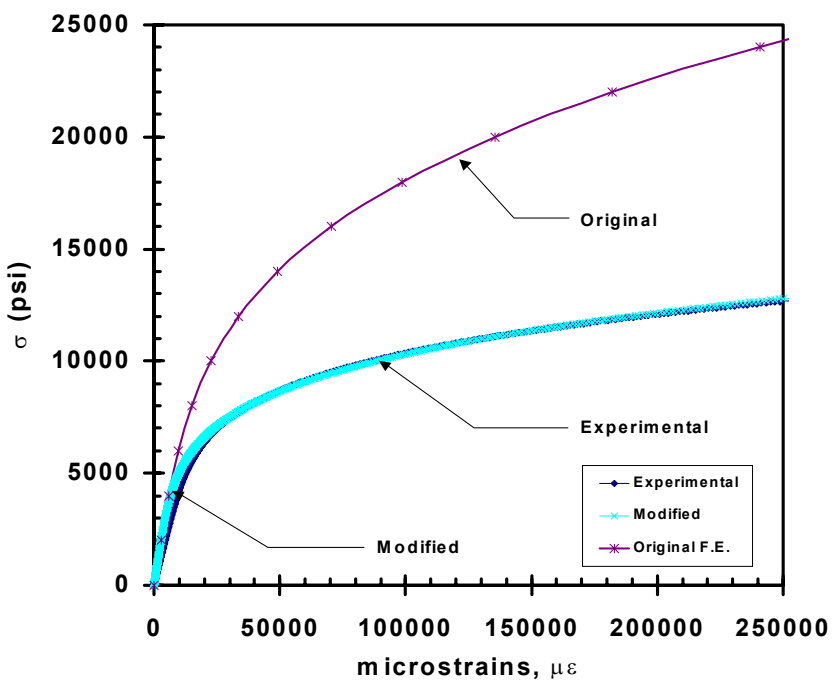

Figure 5: Uniaxial stress-strain curve of matrix used in finite element model

\begin{tabular}{|l|r|r|c|}
\hline \multicolumn{1}{|c|}{ Properties } & Experimental Data & \multicolumn{1}{|c|}{ Computational Data } & \% error \\
\hline $\mathrm{E}_{\mathrm{x}}$ & $12.89 \mathrm{GPa}$ & $12.44 \mathrm{GPa}$ & 3.49 \\
& $1.87 \mathrm{Msi}$ & $1.80 \mathrm{Msi}$ & \\
\hline $\mathrm{E}_{\mathrm{y}}$ & $27.18 \mathrm{GPa}$ & $26.92 \mathrm{GPa}$ & 0.96 \\
& $3.94 \mathrm{Msi}$ & $3.90 \mathrm{Msi}$ & \\
\hline $\mathrm{G}_{\mathrm{xy}}$ & $4.80 \mathrm{GPa}$ & $5.42 \mathrm{GPa}$ & 10.0 \\
& $0.70 \mathrm{Msi}$ & $0.77 \mathrm{Msi}$ & \\
\hline
\end{tabular}

* Note that the value of $G_{x y}$ is provided by supplier and not measured by $A C L$. The measured values for the other moduli were generally higher; approximately $10 \%$ higher.

Table 5: Computational model elastic moduli verification
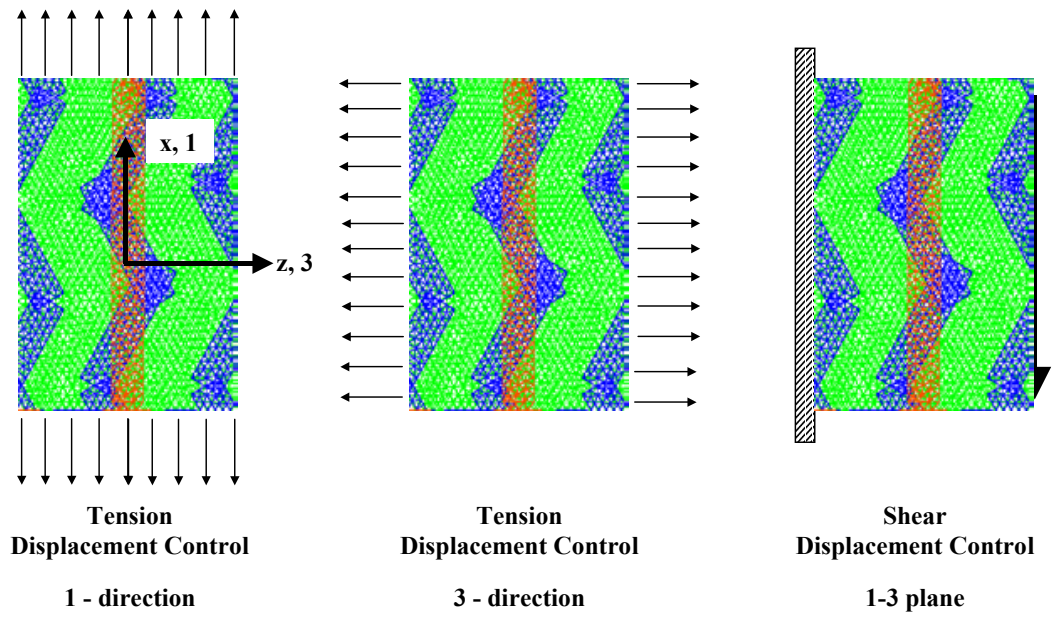

Figure 6: Loading conditions for obtaining elastic moduli 


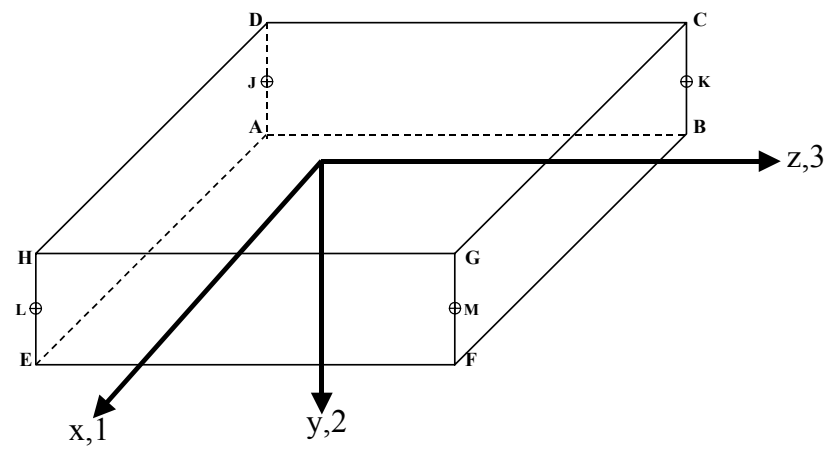

Figure 7: Boundary location of micromodel where displacement constraints are applied

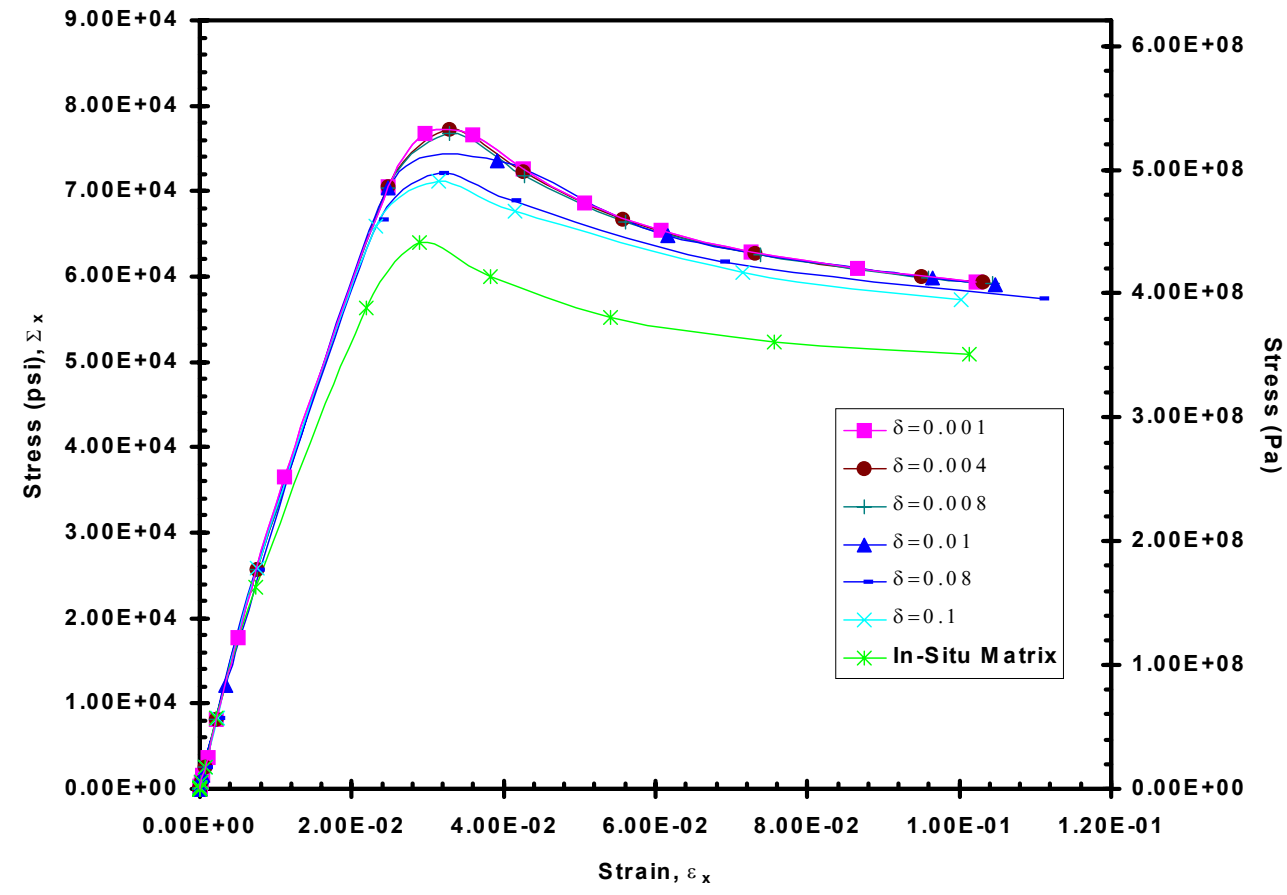

Figure 8: Macroscopic stress-strain relationship under the influence of different imperfections and nonlinear material properties of the micromodel.

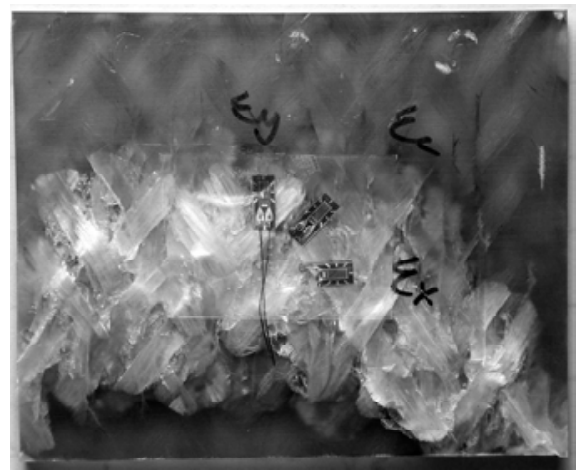

Figure 9: Typical tow buckling phenomenon seen in compression tests. The whitening of the matrix is due to distributed matrix cracking and fiber/matrix debonding 


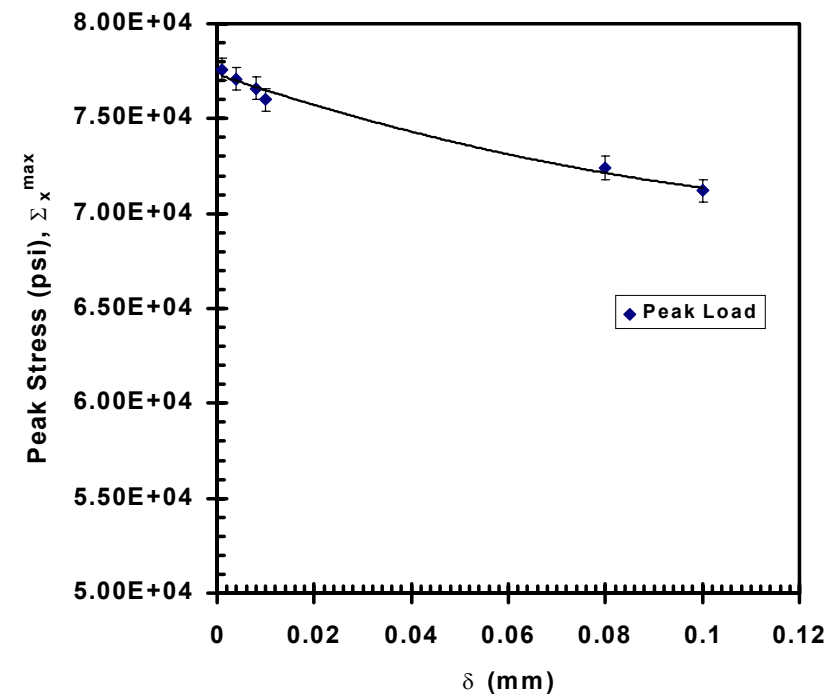

Figure 10: Relationship between imperfection magnitude, $\delta \mathrm{mm}$, and peak stress (psi).

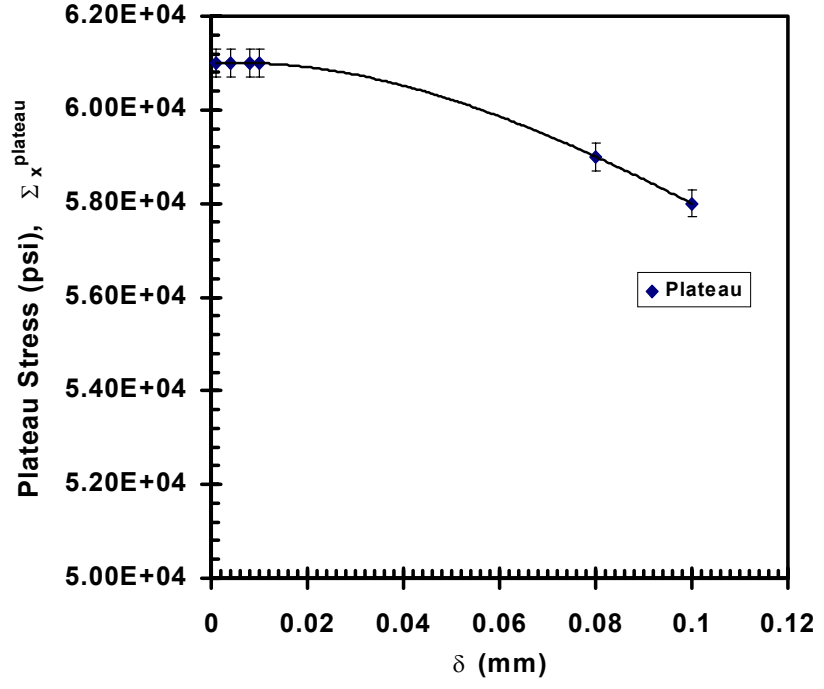

Figure 11: Relationship between imperfection magnitude, $\delta \mathrm{mm}$, and plateau stress (psi) taken at $9 \%$ strain.

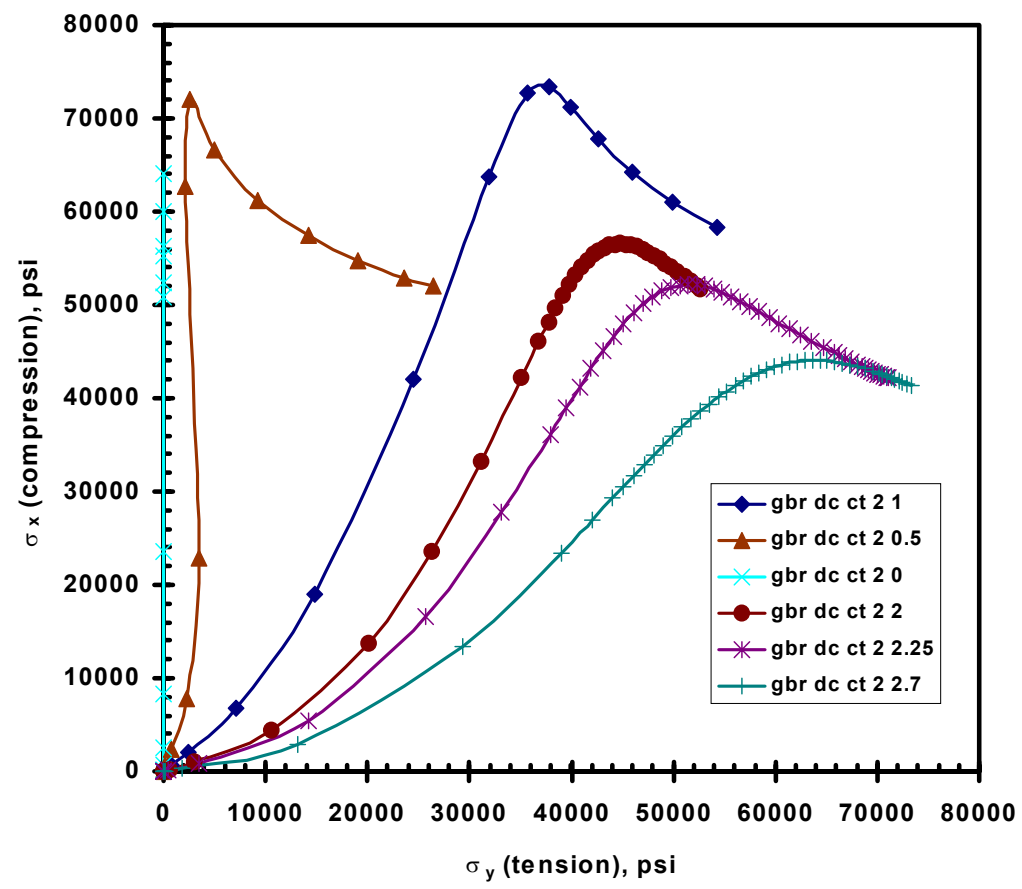

Figure 12: Compressive Stress, $\sigma_{x}$ versus Tensile Stress, $\sigma_{y}$ 


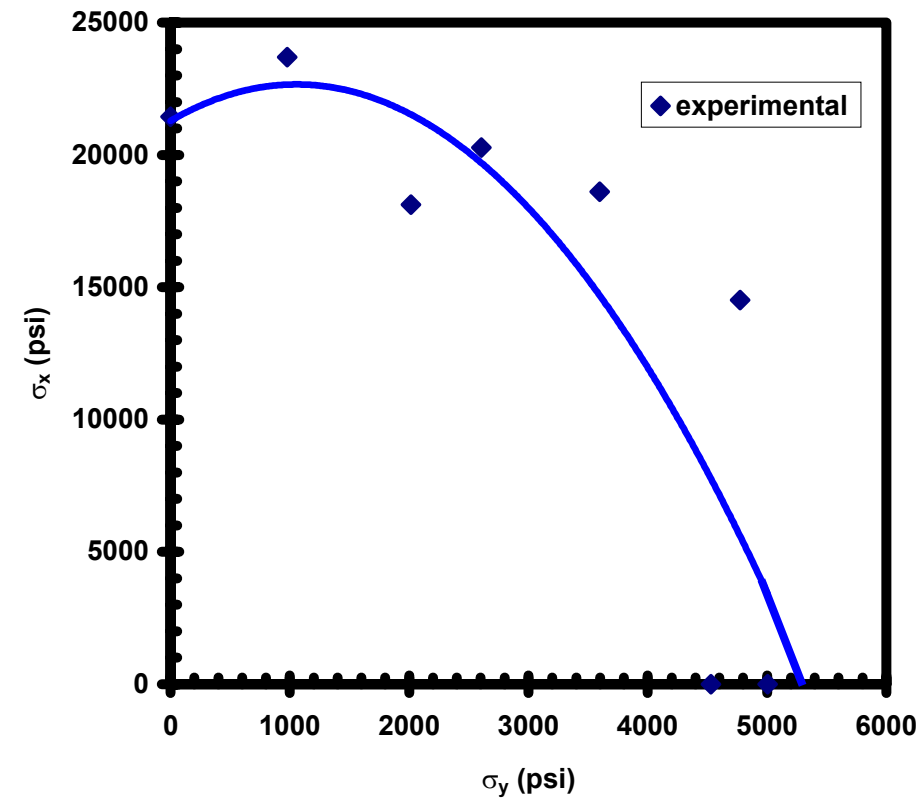

Figure 13: Experimental Failure Envelope for Glass Braided Composite $+30^{\circ} / 0^{\circ} /-30^{\circ}$

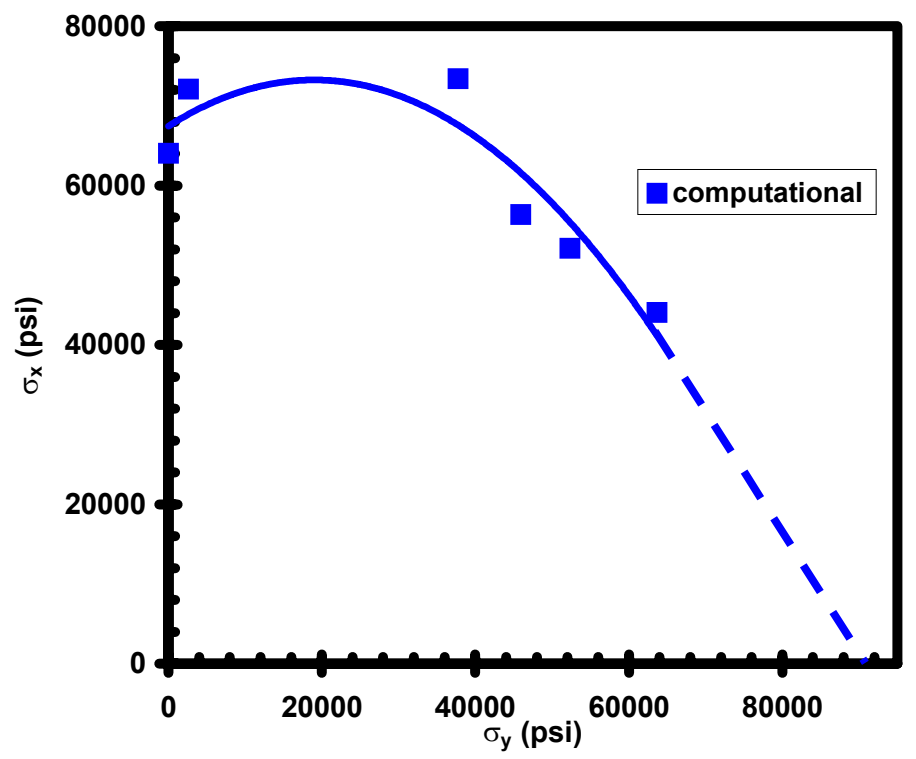

Figure 14: Computationally Predicted Failure Envelope for Glass Braided Composite $+30^{\circ} / 0^{\circ} / \mathbf{3 0}^{\circ}$ 